\title{
Значение 24/7 Сети контактных центров по иностранным боевикам-террористам Совета Европы
}

\section{Альберт Флорес-Херера ${ }^{a}$ и Пламен П. Пенев ${ }^{b}$}

a Конгресс местных и региональных властей, Совет Европы, https://www.coe.int/en/web/congress/home

b Институт всемирной истории Венского университета, https://www.univie.ac.at/en

Резюме: В этой статье рассматривается круглосуточная Сеть контактных пунктов по иностранным боевикам-террористам Совета Европы, предусматриваемая статьей 7 Дополнительного протокола к Конвенции Совета Европы по превенции терроризма от 22 октября 2015 года. Протокол дополняет Конвенцию Совета Европы по превенции терроризма и вступил в действие 1 июля 2017 года. Протокол рассматривает надвигающуюся угрозу безопасности, исходящую из «иностранных боевиков-террористов» (ИБТ), которые возвращаются в страны своего происхождения или пытаются перейти в третьи страны в результате военного поражения и распада ДАИШ. Эти «возвращенцы», т.е. ИБТ и их семьи, являются для правоохранительных органов и обществ всей Европы огромной проблемой, не имеющей простого решения и борьба с этой угрозой требует полного соблюдения международного права.

Ключевые слова: Дополнительный протокол, Конвенция о превенции терроризма, обмен информацией, иностранные боевики-террористы, Совет Европы, Резолюция ООН 2178, 24/7 сеть, Европол, Европейский контртеррористический центр. 


\section{Дополнительный протокол к Конвенции Европейского совета}

\section{по предупреждению терроризма}

В этой статье рассматривается круглосуточная сеть контактных пунктов по иностранным боевикам-террористам Совета Европы (далее «Сеть») предусматриваемая статьей 7 дополнительного протокола к Конвенции Совета Европы по предупреждению терроризма (далее «Протокол»), который был принять 22 октября 2015 года в Риге, Латвия. Протокол дополняет Конвенцию Совета Европы по превенции терроризма от 2005 года (далее «Конвенция от 2005») и вступил в действие 1 июля 2017 года. Протокол занимается нависшей угрозой безопасности, которая исходит от «иностранных боевиков-террористов» (далее «ИБТ»), которые возвращаются в страны своего происхождения или пытаются переехать в третьи страны в результате краха (военного поражения) ДАИШ. Эти «возвращенцы» - ИБТ и их семьи - являются огромной проблемой для органов охраны правопорядка и для обществ по всей Европе, которая не имеет простого решения и борьба с этой опасностью требует полного соблюдения международного права.

Таким образом Протокол является продолжением Резолюции ООН 2178 (2014), которая дала юридические обязательства в связи с криминализацией подготовки терактов, совершения терактов и осуществления или принятия на своей территории подготовки террористов. ${ }^{1}$ В результате принятия Резолюции ООН 2178 (2014), Комитет экспертов по терроризму (КОДЕКСТЕР-ККТСЕ) Совета Европы призвал к созданию комиссии, которой было поставлена задача составить Дополнительный протокол к Конвенции по превенции терроризма от 2005 года (Договор № 196). Окончательный проект был закончен в 2015 году после углубленных обсуждений и консультаций с Парламентской ассамблеей Совета Европы.

Дополнительный протокол предусматривает уголовную ответственность за следующие деяния:

- Участие в деятельности объединения или группы с целью совершения или оказания содействия совершению одного или более террористических преступлений (Статья 2);

- Получение подготовки для террористических действий (включая получение знаний или практических умений) в изготовлении или использовании взрывных устройств, огнестрельного оружия, боевых или опасных веществ, или других конкретных методов и технологий, с целью совершения террористических преступлений (Статья 3);

1 "Threats to International Peace and Security Caused by Terrorist Acts," S/RES/2178 (2014), UN Security Council, September 24, 2014, http://unscr.com/files/2014/02 178.pdf. 
- Поездка в страну, отличную от места жительства или национальности, с целью совершения или содействия совершения террористического преступления, или предоставления или получения подготовки к террористическим действиям (Статья 4);

- Оказание прямой (косвенной) финансовой поддержки или сбор средств полностью или частично обеспечивающих поездку какоголибо лица за границу с целью осуществления актов терроризма (Статья 5);

- Организация поездки или содействие другим способом поездки за границей какому-либо лицу с целью осуществления актов терроризма (Статья 6).

\section{Иностранные боевики-террористы (ИБТ)}

Есть разные определения термина «Иностранный боевик-террорист», но в целом принято, что этот термин применим к лицам некоренного населения, которые решили уехать из страны своего происхождения и принять участие в повстанческих (военных) боевых действиях в иностранных зонах конфликтов без обещания о денежном вознаграждении. ${ }^{2}$ Соответственно, исламские ИБТ определялись как (не)оплачиваемые боевики, не имеющих никакой видимой связи с зоной конфликта, кроме как религиозные пристрастия. ${ }^{3}$ Не менее важным является факт, что число ИБТ, связанных с конкретным раздираемый войной регионом, в сочетание со способностями и ноухау, которое они предоставляют местным повстанческим движениям, может играть существенную и даже решающую роль в зоне конфликта (примером чему является сговор моджахедов с движением Талибан во время афганского конфликта в 1980-х, или ИБТ в боснийском и чеченском конфликтах в 1990-х). Согласно данным, предоставленным заместителем Генерального секретаря ново созданного Управления по борьбе с терроризмом ООН, господином Владимиром Воронковым, как минимум 5600 ИБТ из 33 стран уже вернулись домой. ${ }^{4}$ Многие из них выпали из поля зрения органов охраны правопорядка и поскольку они получили серьезную подготовку и были основательно экипированы во время, проведенного на контролированных

2 Для детального обсуждения академического термина «Иностранный боевиктеррорист» см. Sandra Kraehenmann, "Foreign Terrorist Fighters under International Law," Academy Briefing no. 7 (Geneva: Geneva Academy of International Humanitarian Law and Human Rights, October 2014), 5-7, www.geneva-academy.ch/joomlatoolsfiles/docman-files/Publications/Academy\%20Briefings/Foreign\%20Fighters_2015_ WEB.pdf.

3 Thomas Hegghammer, "The Rise of Muslim Foreign Fighters: Islam and Globalization of Jihad," International Security 35, no. 2 (Winter 2010-2011), 53.

4 См. еще Richard Barrett, Beyond the Caliphate: Foreign Fighters and the Threat of Returnees (New York: The Soufan Center and the Global Strategy Network, October 2017), по состоянию на 19 июня 2018, http://thesoufancenter.org/research/ beyond-caliphate. 
ДАИШ территориях, многие из них способны создать хаос в результате совершения терактов в своих родных странах. Кроме того, из виду не следует упускать еще два аспекта - радикализацию и готовность вербовать последователей для службы ДАИШ.

Хотя ДАИШ потерпело поражение, его идеология еще жива и может быть экспортирована по всему миру в результате возвращения ИБТ. Поэтому от Совета Европы и государств членов ООН требуется расширить сотрудничество и обмен информацией, создать надежную систему проверки в плане безопасности на границах, синхронизировать и усовершенствовать свою систему уголовного правосудия в соответствие с верховенством закона и стандартами прав человека. Учитывая, что угроза, каковой являются ИБТ, все еще остается, ${ }^{5}$ и для того, чтобы облегчить обмен информацией, для европейской безопасности критически важно, чтобы государства-члены Совета Европы и ЕС 6 на практике применяли Статью 7 Протокола, ${ }^{7}$ которая требует создания сети специальных национальных пунктов, которые дали бы 47 государствам-членам возможность обмениваться полицейской информаций «касающейся лиц, отправляющихся за границу с целью участия в террористических действиях», что означает: лица, подозреваемые в плани-

5 После потери почти всей своей территории, стратегия ДАИШ на 2018 год, похоже, указывает на перегруппировку ее членов в Сирии и Ираке, на сохранение угрозы путем совершения терактов с большим числом жертв и использованием простых средств и вынуждения ее сторонников к совершению нападений в своих родных странах. Относительно будущей информации, смотри Matthew Henman, "Global Militant Attacks Caused Fewer Fatalities in 2017," IHS Markit, January 18, 2018, https://ihsmarkit.com/research-analysis/global-militant-attacks-caused-fewerfatalities-in-2017.html.

6 ЕС ратифицировал Протокол 22 октября 2015 года и в заявлении, опубликованном до ратификации, комиссар Д. Аврамополус (Миграция, внутренние дела и гражданство) комментировал текст, подчеркнув значение Протокола: «Сегодня мы делаем важный шаг вперед в борьбе с проблемой глобальной безопасности конкретными, законными средствами. Борьба с терроризмом является высшим приоритетом на будущие годы и сегодняшнее подписание Протокола даст Европейскому Союзу подходящий набор инструментов для этого».

7 Статья 7 (Обмен информацией) гласит:

1. Без нарушения Статьи 3, параграф 2, подпараграф «а» Конвенции [о превенции терроризма] и в соответствие с национальным законодательством и существующими международными обязательствами, каждая Сторона предпримет такие меры, которые необходимы для улучшения своевременного обмена между Сторонами любой наличной имеющей отношение информации, касающейся поездок за границу с целью осуществления террористических действий, определенных в статье 4. Для этой цели, каждая Сторона определит точку контакта на круглосуточной, каждодневной основе.

2. Сторона может предпочесть назначить уже существующую в соответствие с параграфом 1 точку контакта.

3. Точка контакта каждой Стороны должна иметь возможность осуществлять коммуникации с точками контакта других Сторон в ускоренном порядке. 
ровании, обеспечении или совершении актов терроризма, или предоставляющих или получающих террористическую подготовку. Статья 7 напрямую предусматривает обмен полицейской информацией своевременно и в ускоренном порядке и требует от стран-членов назначить официальные точки контакта, которые будут быстро коммуникировать и обмениваться полицейской информаций об ИБТ со своими партнерами.

Однако, юридические эксперты, занимающиеся 24/7 Сетью контактных центров по ИБТ Совета Европы, выражали опасения относительно ее функционирования и ссылались на недостатки, которые предполагаемое сотрудничество между сторонами Протокола может выявить. В качестве примера плохой коммуникации и запоздалого обмена полицейской информацией стоить привести случай в Берлине осуществившего нападения с использованием грузовика г-на Аниса Амри, который убил 12 человек и ранил более 60 на рождественском базаре 19 декабря 2016, ${ }^{8}$ расследование которого выявило множество пропусков со стороны германских властей и пролило свет на недостаточное сотрудничество и обмен соответствующими данными, касающихся подозреваемого, между полицейскими силами в Германии. ${ }^{9}$

Учитывая эти моменты и для того, чтобы смягчить последствия потенциальных будущих промахов, КОДЕКСТЕР-КСЕКТ проверил эффективность Сети с целью установить, как национальные контактные центры взаимодействуют между собой и в какой степени ценная информация об ИБТ обменивается и соответственно передается. По сути дела КОДЕКСТЕР-КСЕКТ стремится к улучшению обмена связанными с ИБТ данными преодолевая недоверие, которое преобладало в последние годы между органами охраны правопорядка и внутри разведывательных сообществ и которое мешало быстрому обмену надежной информацией.

\section{Состояние вопроса}

18 мая 2016, на встрече министров в болгарской столице София, Комитет министров Совета Европы «призвал к быстрому созданию 24/7 контактных центров для облегчения своевременного обмена информацией, как это предусмотрено Дополнительным протоколом к Конвенции Совета Европы

8 "Berlin Christmas market attack: Inquiry accuses police of 'sloppiness' in Anis Amri case," Deutsche Welle, October 12, 2017, http://www.dw.com/en/berlin-christmasmarket-attack-inquiry-accuses-police-of-sloppiness-in-anis-amri-case/a-40924403.

9 Что касается доклада г-на Бруно Йоста, бывшего специального прокурора, назначенного Берлинским парламентом для проведения парламентского расследования теракта на рождественской ярмарке, смотри “Abschlussbericht des Sonderbeauftragten des Senats für die Aufklärung des Handelns der Berliner Behörden im Fall AMRI," https://www.berlin.de/sen/inneres/presse/weitere-informationen/ artikel.638875.php. 
по предупреждению терроризма (CETS No. 217), до его вступления в силу». ${ }^{10}$ Ново созданная Сеть начала работать 1 декабря 2016 года и она охватывает 41 назначенных контактных пунктов, включая один для ЕС. КОДЕКСТЕРКСЕКТ провел первую встречу представителей контактных центров 17 октября 2016 в своей штаб-квартире в Страсбурге, дав участникам возможность подробно обсудить такие ключевые вопросы, касающиеся Сети, как ее потенциальная добавленная стоимость, технические подробности, связанные с обеспечением быстрого и безошибочного обмена информацией, защита источников информации и конфиденциальность предоставляемой информации. В результате первой встречи, КОДЕКСТЕР-КСЕКТ и участвующие в Протоколе стороны пришли к соглашению по вопросу о ключевом значении Сети в качестве надежного информационного хаба, который позволит контактным центрам «запрашивать, отправлять и получать информацию с глазу на глаз от других контактных пунктов и канализировать такие запросы или информацию для других соответствующих национальных властей без замедления». ${ }^{11}$

Вторая встреча представителей назначенных контактных пунктов состоялась 21 марта 2017 в Страсбурге, где эксперты КОДЕКСТЕР-КСЕКТ вместе с национальными представителями контактных центров Сети оценили эффективность и точность Сети на основе собранных данных и накопленного опыта. Кроме того, встреча ставила задачу устранения слабостей в оперативной готовности контактных центров, улучшения результативности установленных коммуникационных каналов, проверки точности наиболее часто используемых данных и установления скорости Сети. Проводились обширные дискуссии по вопросу как дальше улучшать Сеть и как идентифицировать и преодолевать непредвиденные или неожиданные проблемы, в больших подробностях обсуждались предложения и задачи, связанные с усовершенствованием системы. Секретариат КОДЕКСТЕР-КСЕКТ информировал назначенных представителей контактных центров об окончательных результатах «пинг теста», проведенного для проверки и оценки оперативного и функционального статуса Сети.

\section{«Пинг тест»}

«Пинг тест» представлял собой отправление электронной почты всем контактным центрам с требованием быстрейшим образом подтвердить ее получение. В этом плане, стороны Протокола и КОДЕКСТЕР-КСЕКТ подтвердили необходимость проводить в будущем еще «пинг тесты» для оценки

10 List of Decisions of the Committee of Ministers of the Council of Europe on "Tackling violent extremism and radicalisation leading to terrorism," $126^{\text {th }}$ Session of the Committee of Ministers of the Council of Europe, Sofia, Bulgaria, May 18, 2016, https://rm.coe.int/1680650870.

11 CODEXTER, "24/7 Network of Contact Points on Foreign Terrorist Fighters Information provided by the Secretariat," CODEXTER (2017) 3, Strasbourg, France, May 4, 2017, https://rm.coe.int/168070f25a. 
эффективности и быстродействия Сети. В рамках «пинг теста» наглядно было полазано, что исключительно важно, чтобы все участники были легко доступны на 24/7 основе при обмене информации через Сеть. Участвующие стороны приняли к сведению рекомендации и заключения, полученные в результате «пинг теста», и пришли к соглашению о необходимости усиления сотрудничества между назначенными лицами для контакта, с одной стороны, и между Секретариатом Совета Европы и национальными лицами для контакта, с другой. ${ }^{12}$

Предвидится третья встреча представителей контактных центров, назначенная на апрель 2019 года, на которой представители национальных контактных центров поделятся опытом и информацией со своими партнерами и Секретариатом Совета Европы о том, как действует Сеть в разных странах и как Сеть функционирует в рамках национального законодательства. Национальным контактным центрам будет дана возможность поделиться с партнерами примерами лучших практик, а также разработать стратегию для повышения взаимного доверия при обмене информацией, касающейся ИБТ. Кроме того, обратная связь по эффективности Сети будет способствовать усовершенствованию установленных коммуникационных каналов (электронная почта, телефон).

\section{7 больше, чем $28(-1)$}

Учитывая состав Совета Европы, европейской международной организации, состоящей из 47 государств-членов - по сравнению с ЕС - 28 минус 1 рекомендуется, чтобы участвующие государства приняли меры для:

- Обмена информацией по Иностранным Боевикам Террористам с использованием 24/7 Сети надежным и быстродействующим образом, поскольку своевременный обмен информацией является ключевым для идентификации ИБТ и для того, чтобы помешать им пересекать границы;

- Учета того, что Совет Европы состоит из 47 государств-членов, среди которых Турция, Албания, БЮРМ, Россия, Азербайджан, Черногория, Босния и Герцеговина, страны из которых многие ИБТ сотрудничали с ДАИШ в периоде 2014-2017 и чьи возвращенцы уже двинулись обратно в свои родные страны; ${ }^{13}$

12 CODEXTER, "24/7 Network of Contact Points on Foreign Terrorist Fighters - Information provided by the Secretariat - Update," CODEXTER (2017) 3rev, Strasbourg, France, November 3, 2017, https://rm.coe.int/updated-information-document-on24-7-ftf-network/1680764662.

13 Относительно более точной информации, связанной с данными и точными числами, смотри доклады, опубликованные Центром Суфан: Richard Barrett, Beyond the Caliphate: Foreign Fighters and the Threat of Returnees; Foreign Fighters: An Updated Assessment of the Flow of Foreign Fighters into Syria and Iraq (December 2015); и Richard Barrett, Foreign Fighters in Syria (June 2014). 
- Полагания и в будущем на такие существующие инструменты для обмена информацией и разведданными по ИБТ, как база данных перемещающихся лиц Европола «Фокусная точка», Сетевое приложение для надежного обмена информацией Европола (SIENA) и Европейская информационная система (EIS), Шенгенская информационная система второго поколения (SIS II), Prüm Connections и Контртеррористический центр Интерпола и Глобальная коммуникационная система полиции I-24/7 и гарантированию их оперативной совместимости;

- Обмена данных Сети с Европейским контртеррористическим центром Европола (ЕКТЦ) для идентификации и принятия мер в отношение ИБТ, поскольку международное сотрудничество между контртеррористическими органами является критически важным;

- Регулярного проведения «пинг тестов» и предоставления результатов контактным центрам для дальнейшей оценки, давая таким образом возможность для предложений и идей о том, как постоянно улучшать характеристики Сети;

- Поощрения государств-членов Совета Европы увеличивать поток информации в Сети, незамедлительного ответа на запросы, сделанные другими государствами, когда необходима информация о ИБТ, и оптимизации информации со странами партнерами, учитывая то, что после краха ДАИШ ИБТ попытаются найти новые убежища, например Ливия, или вернутся в страну происхождения и станут непосредственной угрозой для внутренней безопасности затронутых государств;

- Пропагандировать 24/7 Сеть Совета Европы контактных центров по Иностранным Боевикам Террористам в качестве эффективного инструмента для борьбы с ИБТ и более эффективно следить за новыми тенденциями и маршрутами;

- Публикации анализа случаев, связанными с успешным обменом информации по ИБТ в реальном времени, демонстрирующие функционирование Сети и подчеркивать факт, что быструю и точную коммуникацию между затронутыми участниками можно считать существенной для идентификации потенциала ИБТ и предупреждения пересечения ими европейских границ с целью совершения террористических действий;

- Предотвращение потенциального использования Сети некоторыми государствами членами для решения их внутренних политических проблем, как например включение невинных людей в список ИБТ и квалификации их в качестве ИБТ только потому, что они являются оппонентами режима. Надо упомянуть, что страны по Протоколу должны уважать стандарты и обязанности, связанные с правами че- 
ловека, включая Европейскую конвенцию о правах человека и Международный пакт о гражданских и политических правах, особенно когда речь идет о криминализации подготовки терактов (как предусмотрено Статьей 8 Протокола). ${ }^{14}$

- Подписания и ратификации Протокола, так как до сих пор он ратифицирован 10 членами Совета Европы, а другие 28 государств-членов и ЕС подписали, но еще не ратифицировали Протокол;

- Усиления сотрудничества между международными органами, занимающимися борьбой с терроризмом - Исполнительный директорат Контртеррористического комитета ООН (ИДКТК), Управление ООН по наркотикам и преступности (УНП ООН), Организация по безопасности и сотрудничеству в Европе (ОБСЕ), Европейский контртеррористический центр Европола (ЕКТЦ), Глобальный контртеррористический форум (GCTF) и Центр передового опыта в борьбе с терроризмом НАТО в Анкаре (в Албании скоро будет организован Центр передового опыта НАТО по иностранным боевикам).

\section{Об авторах}

Альберт ФЛОРЕС-ХЕРЕРА работает в Конгрессе местных и региональных властей Совета Европы, в частности по предотвращению коррупции и утверждению прозрачности на местном и региональном уровне. До этого он занимал другие должности в Совете Европы в сфере уголовного права и контртерроризма. Эго профессиональная биография включает опыт в Европоле, в Европейской Комиссии и в Управлении по наркотикам и преступности ООН.

Пламен П. ПЕНЕВ в данное время является сотрудником Института всемирной истории Венского университета. Он закончил Венский университет по специальности социология с дополнительной специализацией по политологии и массовым коммуникациям. В 2011 году он закончил свою диссертацию на соискание научной степени кандидата наук по международным делам в Венском университете. Он был приглашенным научным сотрудником при ДВЗЯИ ООН, ГД НИиИ Комиссии ЕС, ИЕУ Флоренции, Совет Европы - КОДЕКСТЕР, Евроюст и Института международных отношений в Праге. Его основные исследовательские интересы лежат в сфере разоружения, контроля над вооружениями, нераспространения ядерного оружия/ ОМУ, ПЗЯИ, ДНР, свободных от ядерного оружия зон (СЯОЗ) -УДР ООН.

E-mail: penplam@outlook.com.

14 Относительно дополнительной информации об условиях и гарантиях Протокола, смотри его Объяснительный доклад, параграфы 69-79, https://rm.coe.int/16804 7c5ec. 